\title{
Wormlike Chain Parameters of Poly(hexyl isocyanate) in Dilute Solution
}

\author{
Takashi ITOU, Hideaki ChIKIRI, Akio Teramoto $^{\dagger}$ \\ and S. M. AHARONI* \\ Department of Macromolecular Science, Osaka University, \\ Toyonaka, Osaka 560, Japan \\ *Allied Chemical Corporation, Morristown, New Jersey 07960, U.S.A.
}

(Received September 26, 1987)

\begin{abstract}
Intrinsic viscosity-molecular weight relationships were determined for poly(hexyl isocyanate) in toluene and dichloromethane using a number of narrow-distribution samples covering a wide molecular weight range. The data were analyzed according to the YamakawaFujii-Yoshizaki theory of viscosity of wormlike cylinders, yielding the following values for the persistence length $q$ and molar mass $M_{\mathrm{L}}$ per unit contour length: $q=41-34 \mathrm{~nm}$ and $M_{\mathrm{L}}=730-760$ $\mathrm{nm}^{-1}$ in toluene between 10 and $40^{\circ} \mathrm{C}$ and $q=21 \mathrm{~nm}$ and $M_{\mathrm{L}}=750 \mathrm{~nm}^{-1}$ in dichloromethane at $20^{\circ} \mathrm{C}$. These parameter values are favorably compared with those reported for other solvent conditions for the same polymer.
\end{abstract}

KEY WORDS Poly(hexyl isocyanate) / Wormlike Chain / Persistence Length / Yamakawa-Fujii-Yoshizaki Theory / Chain Stiffness / Stiff Chain / Intrinsic Viscosity /

It is well recognized that solution properties of a polymer are greatly influenced by its stiffness. In order to investigate this influence experimentally, we need polymer samples with varying degrees of stiffness defined explicitly. For this purpose, we have chosen poly(hexyl isocyanate) (PHIC) in this study because it is known as a typical semiflexible polymer, whose dilute solution properties can be well characterized in terms of the wormlike chain model originally due to Porod and Kratky. ${ }^{1-6}$ It has been shown that the persistence length $q$ of this polymer varies appreciably with the solvent conditions employed. ${ }^{5-7}$ Indeed, Conio et al. ${ }^{7}$ estimated $q$ to be 40 and $20 \mathrm{~nm}$ in toluene at $25^{\circ} \mathrm{C}$ and dichloromethane (DCM) at $20^{\circ} \mathrm{C}$, respectively, on the basis of Berger and Tidswell's intrinsic viscositymolecular weight relationship in toluene at $25^{\circ} \mathrm{C}{ }^{8}$ However it will be shown that this relationship differs from ours at low molecular weights, which is difficult to reconcile. Furthermore no information is available about the temperature dependence of $q$ for any polyisocyanates. Therefore we performed another viscosity study on the same polymersolvent systems with particular emphasis on temperature dependence. This paper describes preparation of narrow-distribution samples and their characterization by light scattering, sedimentation equilibrium and gel permeation chromatography (GPC). The data for intrinsic viscosity in toluene and DCM are analyzed according to the theory of Yamakawa, Fujii, and Yoshizaki ${ }^{9,10}$ for intrinsic viscosity of wormlike cylinders to evaluate the wormlike chain parameters, $q$ and $M_{\mathrm{L}}$, the molar mass per unit contour length.

\footnotetext{
${ }^{\dagger}$ To whom correspondence should be addressed.
} 


\section{EXPERIMENTAL}

\section{Poly(hexyl isocyanate) Samples}

Poly(hexyl isocyanate) (PHIC) samples were prepared by polymerization of $n$-hexyl isocyanate according to the method reported by Shashoua et al. ${ }^{11}$ and Aharoni. ${ }^{12}$ Hexyl isocyanate purchased from Kanto Chemical Co., Ltd. was purified by vacuum distillation. Toluene and $N, N$-dimethylformamide were distilled one or two days before the polymerization.

About $10 \mathrm{~g}$ of purified hexyl isocyanate were mixed with a DMF + toluene $(1: 1)$ mixture (ca. $100 \mathrm{~cm}^{3}$ ) in the vessel cooled in a dry ice/ acetone bath $\left(-79^{\circ} \mathrm{C}\right)$. Well-dried sodium cyanide dissolved in toluene was used as a catalyst for the polymerization. The catalyst solution thus prepared was added to the hexyl isocyanate solution stirred by a magnetic bar in an argon atmosphere. Immediately the reaction mixture became turbid and viscous. After being kept for $5 \mathrm{~h}$ at $-79^{\circ} \mathrm{C}$, the reaction was terminated by adding about $100 \mathrm{~cm}^{3}$ of cold methanol, yielding white precipitates of PHIC. The precipitates were collected on a sintered glass filter and rinsed with cold methanol for several times. The polymer dried in vacuo for one day was dissolved in benzene and precipitated into methanol. In this way about $130 \mathrm{~g}$ of PHIC were obtained from 14 batches.

Each batch of PHIC sample was repeatedly fractionated with carbon tetrachloride as a solvent and methanol as a precipitant according to Rubingh and $\mathrm{Yu}^{4}$ Then fractions having nearly the same intrinsic viscosities (in 1-chlorobutane at $25^{\circ} \mathrm{C}$ ) were combined and subjected to further fractionation. This process was repeated two to six times. Finally each fraction was reprecipitated from a benzene solution into methanol, freeze-dried from a benzene solution, dried in vacuo at room temperature, and stored at $-20^{\circ} \mathrm{C}$ until use. Eventually 12 PHIC samples were obtained: W-70, W-5, W-4, W-3, Z-2, J2-2, L-2, K-2,
NRX-12, Z-20, H-14, H-12.

\section{Solution Preparation}

All the reagent grade organic solvents used in the present work were distilled before use. Weighed amounts of a given PHIC fraction dried in vacuo overnight and a solvent were mixed in a stoppered flask at room temperature. Then the mixture was stirred by a magnetic bar for one day. However, mixtures containing higher molecular-weight samples ( $\mathrm{H}-14, \mathrm{H}-12)$ were stirred for three to five days at $40^{\circ} \mathrm{C}$ for complete dissolution.

\section{Molecular Weight Determination}

Seven PHIC fractions W-70, W-5, Z-2, L-2, $\mathrm{K}-2$, NRX-12, and Z-20 were analyzed by sedimentation equilibrium with hexane of $25^{\circ} \mathrm{C}$ as a solvent. Use was made of a Beckman-Spinco model E analytical ultracentrifuge with a Kel-F $12 \mathrm{~mm}$ double sector cell and the interference optics with light of $546 \mathrm{~nm}$ wavelength. The length of the liquid column in the ultracentrifuge cell was adjusted to 1.5$3 \mathrm{~mm}$ and the rotor speed was varied from 6000 to $26000 \mathrm{rpm}$ depending on the samples analyzed. Values for the weight-average molecular weight $\bar{M}_{w}$ and the second virial coefficient $A_{2}$ were evaluated using the equation:

$$
M_{\text {app }}{ }^{-1}=\bar{M}_{w}{ }^{-1}+2 A_{2} \bar{c}+\cdots
$$

with

$$
M_{\mathrm{app}}=\frac{2 R T}{\omega^{2}\left(r_{\mathrm{b}}{ }^{2}-r_{\mathrm{a}}{ }^{2}\right)\left(1-v_{\mathrm{p}} \rho_{\mathrm{o}}\right)} \cdot \frac{c_{\mathrm{b}}-c_{\mathrm{a}}}{c_{0}}
$$

where $\bar{c}$ is the average of the mass concentrations $c_{\mathrm{a}}$ and $c_{\mathrm{b}}\left(\mathrm{g} \mathrm{cm}^{-3}\right)$ at the meniscus $r_{\mathrm{a}}$ and the bottom $r_{\mathrm{b}}$, respectively, $c_{0}$ the initial polymer mass concentration, $\omega$ the angular velocity of the rotor, and $\rho_{\mathrm{o}}$ the density of the solvent. For PHIC in hexane of $25^{\circ} \mathrm{C}$, the partial specific volume $v_{\mathrm{p}}$ was taken to be 0.950 $\mathrm{cm}^{3} \mathrm{~g}^{-1}$ and the specific refractive index increment $\partial n / \partial c$ was taken to be $0.129 \mathrm{~cm}^{3} \mathrm{~g}^{-1}$ at $546 \mathrm{~nm}$ and $0.134 \mathrm{~cm}^{3} \mathrm{~g}^{-1}$ at $436 \mathrm{~nm}^{5}$

Fractions $\mathrm{H}-12$ and $\mathrm{H}-14$ were analyzed by 
light scattering with hexane of $25^{\circ} \mathrm{C}$ as a solvent. A Fica 50 automatic photogoniometer was used to measure the Rayleigh ratio $R_{\theta}$ at scattering angles $\theta$ between 22.5 and $150^{\circ}$ for vertically polarized light of 436 and $546 \mathrm{~nm}$ wavelengths with no analyzer. Following Murakami et al., ${ }^{5}$ we neglected optical anisotropy correction.

Osmotic pressures $\Pi$ of fractions $\mathbf{J} 2-2, \mathrm{~K}-2$, and NRX-12 in toluene of $25^{\circ} \mathrm{C}$ were measured on a Knauer osmometer with a Sartorius SM11536 membrane. The cell part of the osmometer was covered with a jacket through which constant-temperature water was circulated and the temperature was controlled within $\pm 0.1^{\circ} \mathrm{C}$.

Zero-shear viscosities of the samples investigated were measured in the following solvents: hexane at $25^{\circ} \mathrm{C}, 1$-chlorobutane at $25^{\circ} \mathrm{C}$, toluene at 10,25 , and $40^{\circ} \mathrm{C}$, and dichloromethane $(\mathrm{DCM})$ at $20^{\circ} \mathrm{C}$. A low-shear fourbulb capillary viscometer was used for fractions $\mathrm{Z}-20, \mathrm{H}-14$, and $\mathrm{H}-12$, whereas conventional capillary viscometers of the Ubbelohde type were used for the other fractions. Intrinsic viscosities $[\eta]$ were estimated by using Mead-Fuoss plots.

All the PHIC samples studied were analyzed by gel permeation chromatography (GPC) using a Toyo Soda $801 \mathrm{~A}$ instrument equipped with a UV detector under the operating conditions: two TSK-Gel GMH columns connected in series; eluent, chloroform; polymer conc, $4 \times 10^{-5} \mathrm{~g} \mathrm{~cm}^{-3}$; injection volume, $0.5 \mathrm{~cm}^{3}$; flow rate, $1 \mathrm{~cm}^{3} \mathrm{~min}^{-1}$; temperature, $40^{\circ} \mathrm{C}$.

\section{RESULTS AND DISCUSSION}

\section{Molecular Characterization}

Figure 1 shows sedimentation equilibrium data for all the PHIC samples studied. The values for $\bar{M}_{w}$ and $A_{2}$ evaluated from the slopes and the intercepts of the indicated straight lines are summarized in Table I. Figure 2 displays plots of $Q v s . \bar{c}$ for the same fractions, with $Q$ defined by ${ }^{13}$

$$
\begin{gathered}
Q=\frac{\left(c_{\mathrm{b}}-c_{\mathrm{a}}\right)^{2}}{\left(r_{\mathrm{b}}{ }^{2}-r_{\mathrm{a}}{ }^{2}\right)\left[\left(\partial c / \partial r^{2}\right)_{r=r_{\mathrm{b}}}-\left(\partial c / \partial r^{2}\right)_{r=r_{\mathrm{a}}}\right]} \\
Q=\left(\bar{M}_{w} / \bar{M}_{z}\right)\left(1+2 A_{2} \bar{c}+\cdots\right)
\end{gathered}
$$

In this figure the straight lines are drawn so that their slopes may be consistent with the $A_{2}$ values determined above. The $\bar{M}_{z} / \bar{M}_{w}$ ratios estimated from the intercepts of the lines are also given in Table I.

Figure 3 shows plots of $K c / R_{0}$ vs. $c$ for fractions $\mathrm{H}-14$ and $\mathrm{H}-12$, where $K$ is the familiar optical constant and $R_{0}$ is the $R_{\theta}$ extrapolated to zero angle, yielding the values of $\bar{M}_{w}$ and $A_{2}$ given in Table I. Figure 4 shows osmotic pressure data, where $(\Pi / R T c)^{1 / 2}$ is

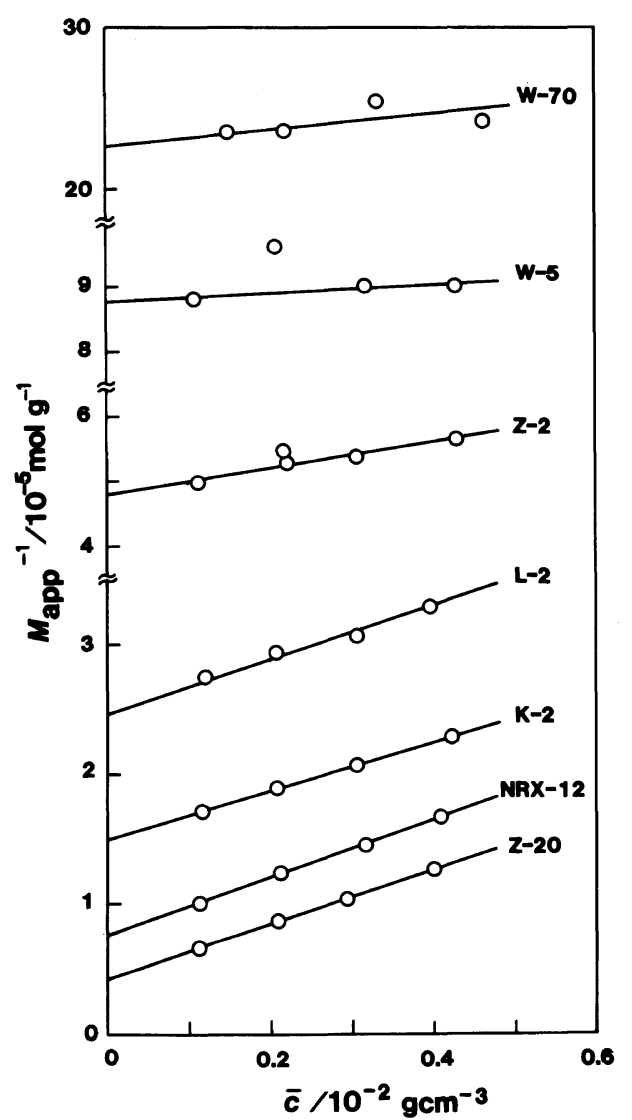

Figure 1. Sedimentation equilibrium data for solutions of PHIC fractions in hexane of $25^{\circ} \mathrm{C}$. 
T. ITOU et al.

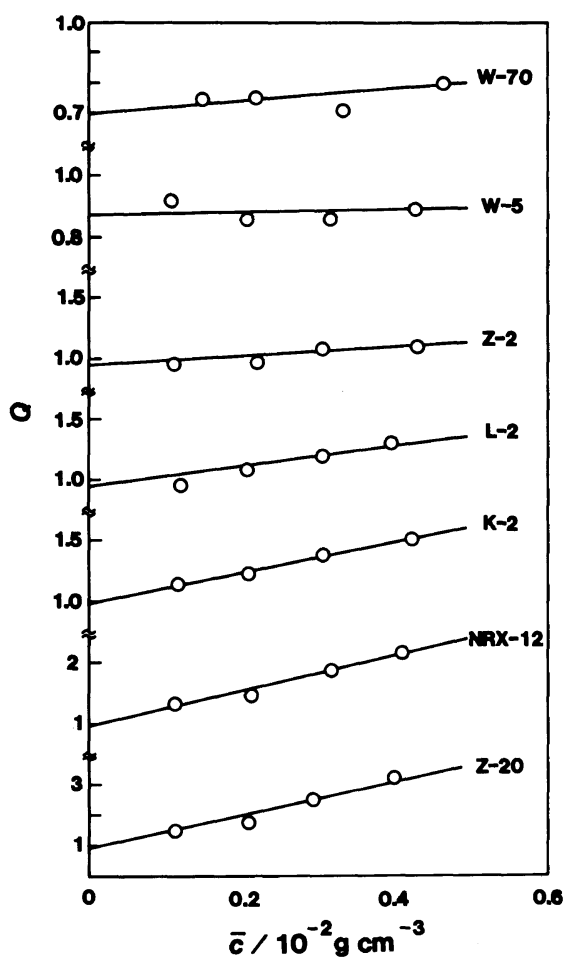

Figure 2. Plots of $Q v s . c$ for PHIC in hexane of $25^{\circ} \mathrm{C}$.

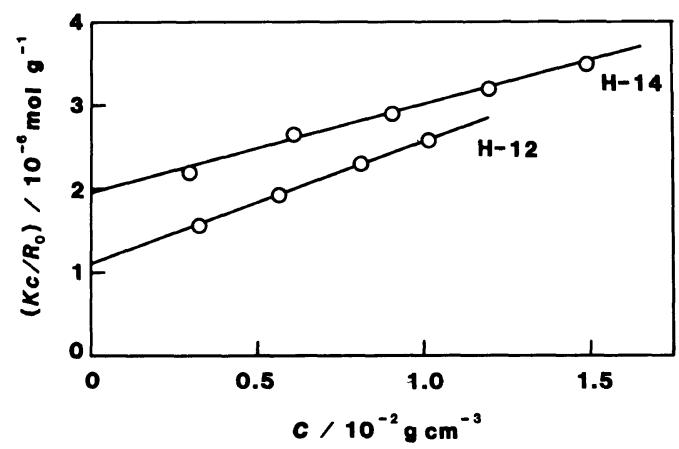

Figure 3. Plots of $K c / R_{0}$ for PHIC fractions in hexane of $25^{\circ} \mathrm{C}$.

plotted against concentration for three fractions. The results are also listed in Table I. It can be seen that the ratio $\bar{M}_{w} / \bar{M}_{n}$ is 1.02 for fraction K-2 and 1.09 for fraction NRX-12.

The elution volume $V_{\mathrm{e}}$ at the maximum of a GPC chromatogram was estimated for each of the nine samples whose $\bar{M}_{w}$ had been measured. Figure 5 shows a plot of $\log \bar{M}_{w} v s . V_{\mathrm{e}}$,
Table I. Molecular parameters of the poly(hexyl isocyanate) samples investigated

\begin{tabular}{lcccc}
\hline & \multicolumn{3}{c}{$A_{2}$} \\
Sample & $\bar{M}_{w} / 10^{3}$ & $\bar{M}_{z} / \bar{M}_{w}\left(\bar{M}_{z} / \bar{M}_{w}\right)^{\mathrm{GPC}}$ \\
\cline { 3 - 5 } & & $10^{-4} \mathrm{molcm}^{3} \mathrm{~g}^{-1}$ & & \\
W-70 & 4.41 & - & - & - \\
W-5 & 11.4 & 3.4 & 1.15 & - \\
W-4 & $12.9^{\mathrm{a}}$ & - & - & 1.045 \\
W-3 & $15.2^{\mathrm{a}}$ & - & - & 1.045 \\
$\mathrm{Z}-2$ & 20.9 & 10.0 & 1.06 & 1.06 \\
J2-2 & $32.0^{\mathrm{a}}$ & - & - & 1.1 \\
& $(30.8$ & $6.2)^{\mathrm{b}}$ & & \\
L-2 & 40.7 & 11.0 & 1.05 & 1.06 \\
K-2 & 68 & 9.8 & 1.02 & 1.06 \\
& $(66.4$ & $9.4)^{\mathrm{b}}$ & & \\
NRX-12 & 133 & 11.2 & 1.05 & 1.05 \\
& $(122$ & $9.7)^{\mathrm{b}}$ & & \\
RX-2 & $162^{\mathrm{a}}$ & - & - & 1.075 \\
Z-20 & 244 & 10.7 & 1.05 & 1.07 \\
H-14 & 510 & 5.3 & - & 1.17 \\
H-12 & 910 & 7.4 & - & - \\
\hline
\end{tabular}

a $\bar{M}_{v}$ calculated from $[\eta]$ in toluene of $25^{\circ} \mathrm{C}$ using the $[\eta]$ vs. $\bar{M}_{w}$ relationship established with the data for the other samples.

b Values in the parentheses: $\bar{M}_{n}$ and $A_{2}$ from osmotic pressure measurements with toluene of $25^{\circ} \mathrm{C}$ as the solvent.

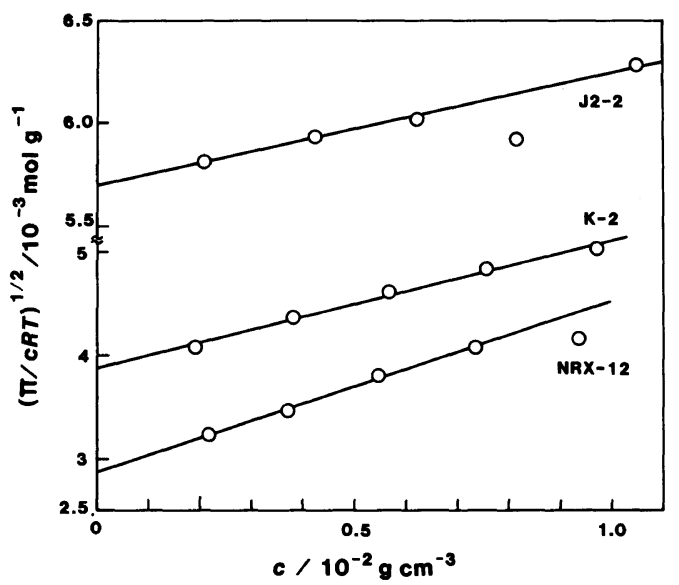

Figure 4. Osmotic pressure data for PHIC fractions in toluene of $25^{\circ} \mathrm{C}$.

where all the data points except those for fractions $\mathrm{W}-70, \mathrm{H}-12$, and $\mathrm{H}-14$ are seen to follow the indicated straight line. In the same figure are shown GPC curves for fractions W5, Z-2, L-2, K-2, NRX-12, Z-20, and H-14 


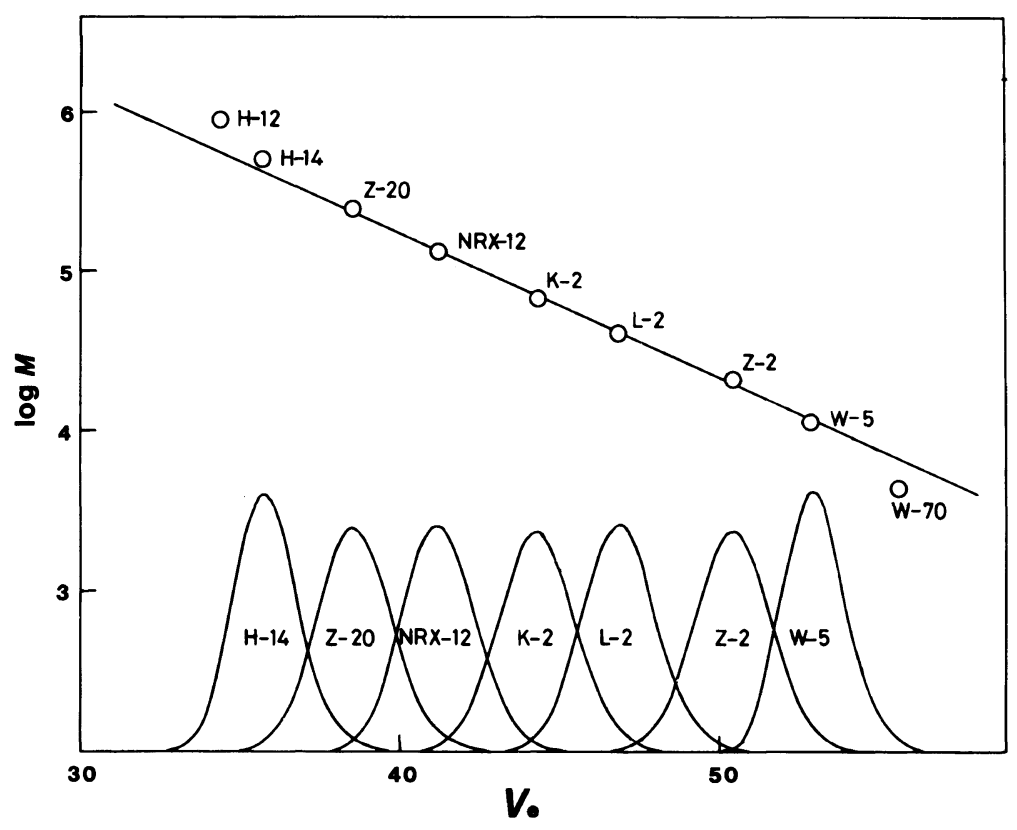

Figure 5. GPC calibration curve for PHIC. $M=\bar{M}_{w}$

each exhibiting a narrow and almost symmetric peak. Similar GPC curves were obtained for the other fractions. Therefore conversion of elution volume $V_{\mathrm{e}}$ to $M$ was made by using

$$
\log M=A V_{\mathrm{e}}+B
$$

where $A$ is the slope of the indicated straight line and $B$ was determined to give the best agreement between observed $\bar{M}_{w}$ and those calculated from the GPC curve.

Figure 6 shows the molecular weight distribution curves computed from the GPC curves for typical fractions using the calibration curve given above. $\bar{M}_{w} / \bar{M}_{n}$ and $\bar{M}_{z} / \bar{M}_{w}$ values evaluated from such distribution curves are designated as $\left(\bar{M}_{w} / \bar{M}_{n}\right)^{\mathrm{GPC}}$ and $\left(\bar{M}_{z} / \bar{M}_{w}\right)^{\mathrm{GPC}}$, respectively, and are summarized in Table $\mathrm{I}$; in all the cases $\left(\bar{M}_{w} / \bar{M}_{n}\right)^{\mathrm{GPC}}=\left(\bar{M}_{z} / \bar{M}_{w}\right)^{\mathrm{GPC}}$ within experimental error. However, for fractions W$70, \mathrm{H}-14$, and $\mathrm{H}-12$, this evaluation was impossible because the calibration curve did not cover their GPC curves completely. Whenever comparison can be made, $\left(\bar{M}_{z} / \bar{M}_{w}\right)^{\mathrm{GPC}}$ is close

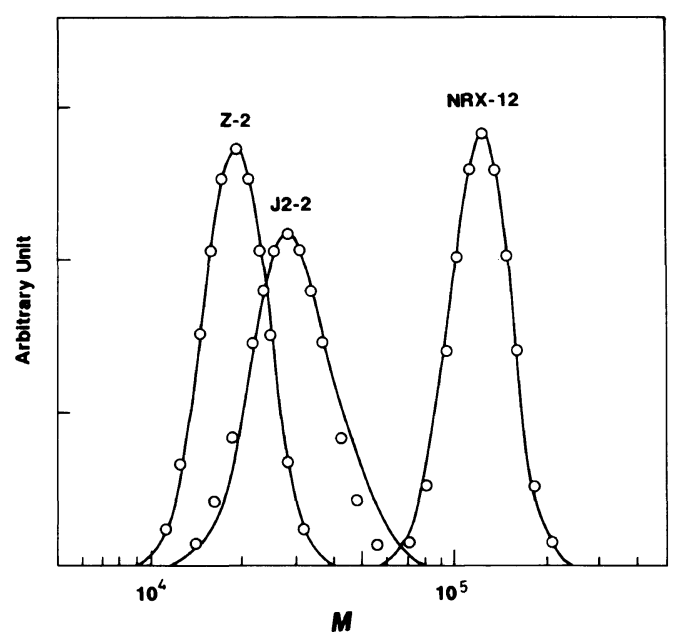

Figure 6. Molecular weight distribution curves for typical PHIC fractions. Solid curves, observed distribution functions; circles, logarithmic normal distributions calculated for the respective $\bar{M}_{z} / \bar{M}_{w}$ values.

to $\bar{M}_{z} / \bar{M}_{w}$ determined by sedimentation equilibrium, indicating that the GPC and sedimentation data are consistent with each other. The values for $\bar{M}_{w} / \bar{M}_{n}, \bar{M}_{z} / \bar{M}_{w}$, $\left(\bar{M}_{w} / \bar{M}_{n}\right)^{\mathrm{GPC}}$, and $\left(\bar{M}_{z} / \bar{M}_{w}\right)^{\mathrm{GPC}}$ are smaller than 
1.05 except for a few sets of data, even for which they do not exceed 1.1. This shows that the molecular weight distributions of the PHIC samples examined are close to monodisperse. Incidentally, it is noted that the observed molecular weight distributions (solid curves) in Figure 6 are well approximated by the distributions (circles) of the logarithmic normal type with the corresponding $\bar{M}_{z} / \bar{M}_{w}$ values.

\section{Viscosity Data}

Table II gives the values of $[\eta]$ for the PHIC samples studied; the $\bar{M}_{v}$ values for fractions W-4, W-3, J2-2, and RX-2 determined using the $[\eta] v s . \bar{M}_{w}$ relationship in toluene at $25^{\circ} \mathrm{C}$ established with the data for the other samples are given in the second column in Table I. It can be seen that $[\eta]$ in toluene decreases significantly with raising temperature. It is also noted that $[\eta]$ is much smaller in DCM than in toluene. This remarkable dependence of $[\eta]$ on solvent condition confirms the pre-
Table II. Intrinsic viscosities of the PHIC samples under various conditions $\mathbf{s}^{\mathbf{a}}$

\begin{tabular}{|c|c|c|c|c|}
\hline \multirow{3}{*}{ Sample } & \multicolumn{4}{|c|}{$[\eta] / 10^{2} \mathrm{~cm}^{3} \mathrm{~g}^{-1}$} \\
\hline & \multicolumn{3}{|c|}{ Toluene } & \multirow{2}{*}{$\frac{\text { Dichloromethane }}{20^{\circ} \mathrm{C}}$} \\
\hline & $10^{\circ} \mathrm{C}$ & $25^{\circ} \mathrm{C}$ & $40^{\circ} \mathrm{C}$ & \\
\hline W-70 & - & 0.0767 & - & - \\
\hline W-6 & - & 0.11 & - & - \\
\hline W-5 & - & 0.181 & - & 0.156 \\
\hline W-4 & - & 0.214 & - & - \\
\hline W-3 & - & 0.268 & - & - \\
\hline $\mathrm{Z}-2$ & 0.433 & 0.418 & 0.404 & 0.348 \\
\hline $\mathrm{J} 2-2$ & 0.802 & 0.778 & 0.746 & - \\
\hline L-2 & 1.14 & 1.10 & 1.04 & 0.838 \\
\hline S2-2 & 1.89 & 1.80 & 1.69 & - \\
\hline K-2 & 2.27 & 2.15 & 2.20 & 1.64 \\
\hline MO-2 & 3.85 & 3.59 & 3.33 & - \\
\hline NRX-12 & 5.14 & 4.78 & 4.40 & 3.32 \\
\hline $\mathrm{RX}-2$ & 6.59 & 5.94 & 5.25 & - \\
\hline Z-20 & 9.97 & 9.10 & 8.27 & 5.84 \\
\hline $\mathrm{H}-14$ & 21.9 & 18.9 & 16.9 & 10.2 \\
\hline H-12 & 35.5 & 32.2 & 28.6 & 17.6 \\
\hline
\end{tabular}

${ }^{\text {a }}$ For all the cases examined, the Huggins viscosity constant $k^{\prime}$ was within $0.30-0.56$.

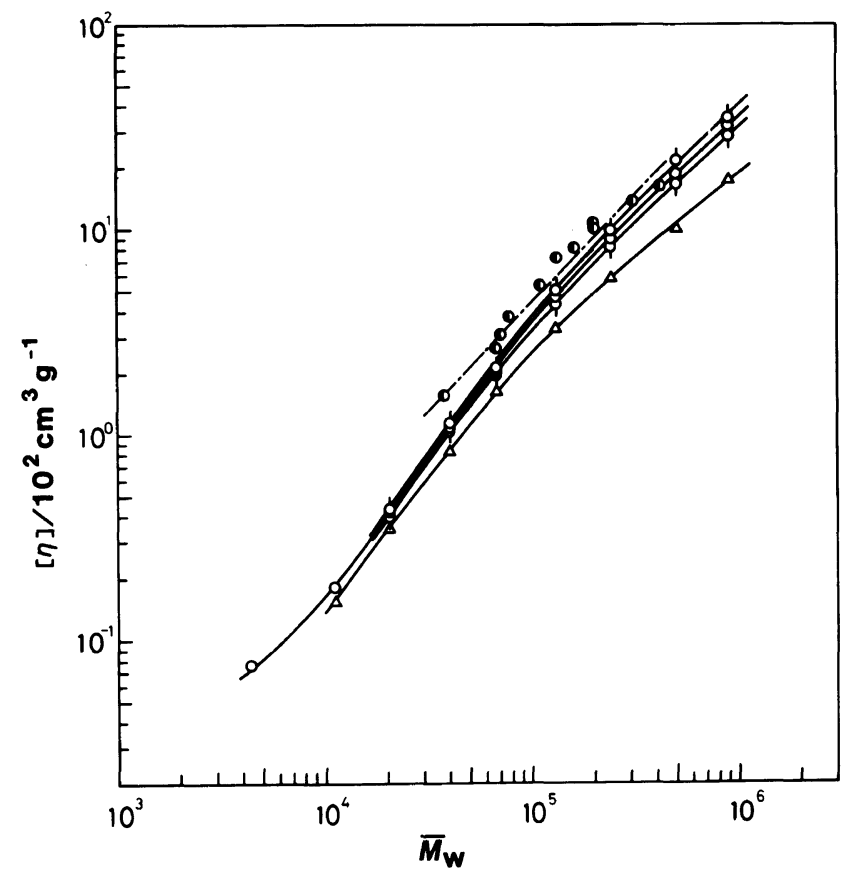

Figure 7. Double logarithmic plots of $[\eta] v s . \bar{M}_{w}$ for PHIC. Solvents: $\triangle, \mathrm{DCM}$ of $20^{\circ} \mathrm{C} ; \bigcirc\left(10^{\circ} \mathrm{C}\right), \bigcirc$ $\left(25^{\circ} \mathrm{C}\right), Q\left(40^{\circ} \mathrm{C}\right)$, toluene; $\bigcirc$, toluene of $25^{\circ} \mathrm{C}$ by Berger and Tidswell. ${ }^{8}$ 
vious observations with this polymer by Berger and Tidswell ${ }^{8}$ and Conio et al. ${ }^{7}$

The double-logarithmic plots of $[\eta]$ against $\bar{M}_{w}$ for the two solvents are shown in Figure 7 . The data points are fitted by the indicated smooth curves convex upward. In this figure, half-filled circles represent the data of Berger and Tidswell ${ }^{8}$ for PHIC in toluene at $25^{\circ} \mathrm{C}$. They appear significantly above ours for the same system especially at lower molecular weights. This discrepancy may not be attributed to the polydispersity of these samples because their $\bar{M}_{w} / \bar{M}_{n}$ are reported to be smaller than $1.1^{8}$ It can be shown that our data in toluene at $25^{\circ} \mathrm{C}$ behave quite similarly to those in 1-chlorobutane at $25^{\circ} \mathrm{C}$ of Kuwata et al. ${ }^{6}$ and those at $40^{\circ} \mathrm{C}$ are very close to the latter. Incidentally, our $[\eta] v s . \bar{M}_{w}$, relationship in 1chlorobutane at $25^{\circ} \mathrm{C}$ precisely confirms that reported by Kuwata et al. ${ }^{6}$

\section{Analysis of Viscosity Data}

Yamakawa and collaborators ${ }^{9,10}$ developed theories of hydrodynamic properties of wormlike cylinders and indicated their applicability to real polymers. Recently, Bushin et $a .^{14}$ and Bohdanecky ${ }^{15}$ independently proposed a simple procedure based on the Yamakawa theory for determining the wormlike chain parameters: the molar mass $M_{\mathrm{L}}$ per unit contour length, persistence length $q$, and diameter $d$ of the cylinder. It uses the equation

$$
\left(M^{2} /[\eta]\right)^{1 / 3}=I+S M^{1 / 2}
$$

with

$$
\begin{gathered}
I=1.516 \times 10^{-8} A_{0} M_{\mathrm{L}}\left(\mathrm{g}^{1 / 3} \mathrm{~cm}^{-1}\right) \\
S=1.516 \times 10^{-8} B_{0}\left(M_{\mathrm{L}} / 2 q\right)^{1 / 2} \\
\left(\mathrm{~g}^{1 / 3} \mathrm{~cm}^{-1}\right)
\end{gathered}
$$

where $M$ is the molecular weight of the polymer and $A_{0}$ and $B_{0}$ are known functions of $d / 2 q$. It has been shown that for $d / 2 q \sim 10^{-2}$ eq 5 is accurate in a wide range of $M /\left(2 q M_{\mathrm{L}}\right)$ from 0.4 to 300 . Equations (5) through (7) contain the three wormlike chain parameters, $M_{\mathrm{L}}, q$, and $d$. It is impossible to determine all these parameters independently from experimentally obtainable quantities $I$ and $S$ only when a plot of $\left(M^{2} /[\eta]\right)^{1 / 3} v s . M^{1 / 2}$ is linear.

Figure 8 shows plots of $\left(\bar{M}_{w}{ }^{2} /[\eta]\right)^{1 / 3} v s$.

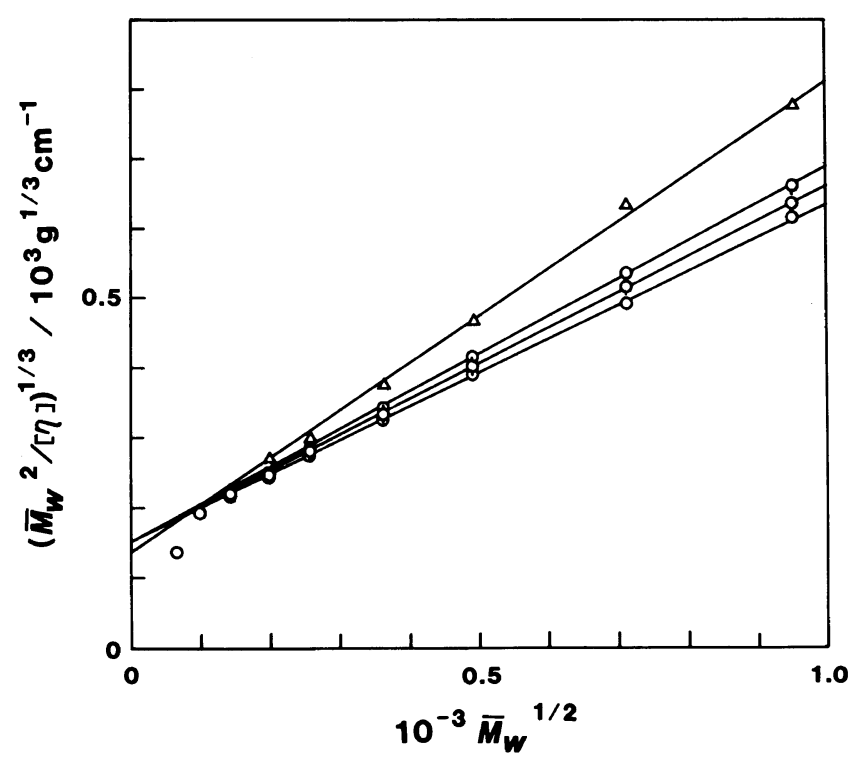

Figure 8. Plots of $\left(\bar{M}_{w}{ }^{2} /[\eta]^{1 / 3} v s . \bar{M}_{w}{ }^{1 / 2}\right.$ for PHIC under the specified solvent conditions. Symbols are the same as those in Figure 7. 
$\bar{M}_{w}{ }^{1 / 2}$ constructed from the data in Table II. It can be seen that the data points for $\bar{M}_{w}{ }^{1 / 2}$ larger than 300 follow closely the indicated straight lines, which allow the intercept $I$ and slope $S$ to be determined with reasonable accuracy. With the values of $I$ and $S$ thus determined for toluene of $25^{\circ} \mathrm{C}$, we sought by trial and error a set of $M_{\mathrm{L}}, q$, and $d$ in the

Table III. Wormlike chain parameters of PHIC

\begin{tabular}{|c|c|c|c|c|}
\hline \multirow{2}{*}{ Solvent } & $T$ & $M_{\mathrm{L}}$ & $q$ & $d$ \\
\hline & ${ }^{\circ} \mathrm{C}$ & $\mathrm{nm}^{-1}$ & $\mathrm{~nm}$ & $\mathrm{~nm}$ \\
\hline \multirow[t]{3}{*}{ Toluene } & 10 & 730 & 41 & $1.6^{\mathrm{a}}$ \\
\hline & 25 & 740 & 37 & 1.6 \\
\hline & 40 & 750 & 34 & $1.6^{\mathrm{a}}$ \\
\hline DCM & 20 & 740 & 21 & $1.6^{\mathrm{a}}$ \\
\hline Hexane $^{5}$ & 25 & 715 & 42 & 1.6 \\
\hline 1-Chlorobutane $e^{6}$ & 25 & 760 & 35 & 1.5 \\
\hline
\end{tabular}

a Assumed value.
Yamakawa-Fujii-Yoshizaki theory for [ $\eta]$ which best fit the experimental data, with the result: $M_{\mathrm{L}}=750 \mathrm{~nm}^{-1}, q=37 \mathrm{~nm}$, and $d=$ $1.6 \mathrm{~nm}$. The data for toluene at other temperatures and DCM at $20^{\circ} \mathrm{C}$ do not cover so wide a range of molecular weight as to permit the above trial and error operation. Therefore they were analyzed with $d$ assumed to be $1.6 \mathrm{~nm}$. All the numerical results thus analyzed are summarized in Table III. Figure 9 compares the experimental $[\eta]$ with the Yamakawa-FujiiYoshizaki theoretical values calculated for these parameter values. The agreement between experiment and theory is satisfactory for all the systems studied.

We now compare the wormlike chain parameters thus determined with those in hexane ${ }^{5}$ and 1-chlorobutane. ${ }^{6}$ It can be seen that $d$ is substantially constant and $M_{\mathrm{L}}$ does not change significantly under the solvent conditions employed. On the other hand, $q$ under-

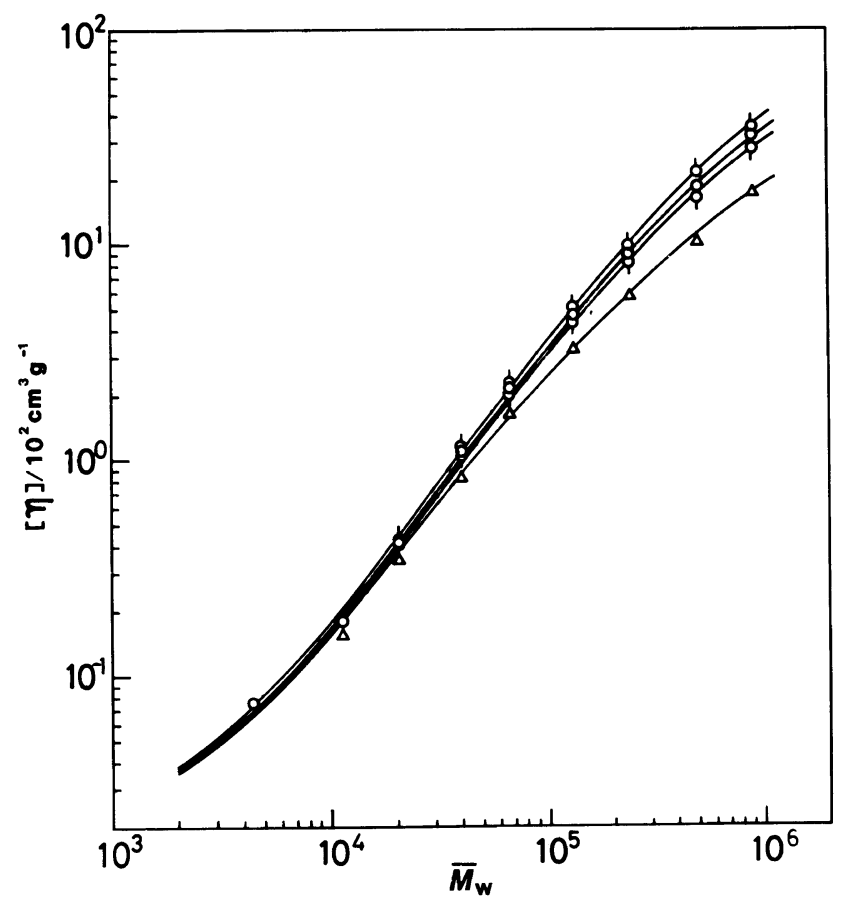

Figure 9. $[\eta]$ of PHIC as functions of $\bar{M}_{w}$. (-) Calculated by the Yamakawa-Fujii-Yoshizaki theory with the parameter values listed in Table III; the same symbols as those in Figure 7 are used to represent the experimental data. 
goes remarkable solvent and temperature effects; it is nearly the same in hexane and in toluene but significantly smaller in DCM. It can be shown that in toluene $q$ decreases with raising temperature $T$ more rapidly than with $T^{-1}$.

A similar analysis of the $[\eta]$ data of Berger and Tidswell $^{8}$ for PHIC in toluene of $25^{\circ} \mathrm{C}$ gave considerably lower values for both $M_{\mathrm{L}}$ and $q$ with any reasonable values assumed for $d ; M_{\mathrm{L}}$ was found to be at most $550 \mathrm{~nm}^{-1}$ more than $20 \%$ lower than those shown above in Table III and those estimated by conformational analysis. ${ }^{16}$ We take our values as correct, although we have no idea to reconcile this discrepancy. Conio et al. ${ }^{7}$ reported $q$ values of 38 and $19 \mathrm{~nm}$ for PHIC in toluene of $25^{\circ} \mathrm{C}$ and in DCM of $20^{\circ} \mathrm{C}$, respectively, which were obtained by analyzing their $[\eta]$ data with $\bar{M}_{v}$ based on the Berger-Tidswell viscosity relationship for toluene solutions; they used a $d$ value of $1.03 \mathrm{~nm}$ obtained from $v_{\mathrm{p}}$ of PHIC and with $M_{\mathrm{L}}$ assumed to be $635 \mathrm{~nm}^{-1}$. However, the excellent agreement of their $q$ values with ours is accidental, because the latter viscosity relationship does not agree with ours.

Acknowledgment. The authors thank Dr.
Takashi Norisuye for valuable discussions and comments.

\section{REFERENCES}

1. O. Kratky and G. Porod, Recl. Trav. Chim., 68, 1106 (1949).

2. A. J. Bur and L. J. Fetters, Chem. Rev., 76, 727 (1976).

3. L. J. Fetters and H. Yu, Macromolecules, 4, 385 (1971).

4. D. N. Rubingh and H. Yu, Macromolecules, 9, 681 (1976).

5. H. Murakami, T. Norisuye, and H. Fujita, Macromolecules, 13, 345 (1980).

6. M. Kuwata, T. Norisuye, and H. Fujita, Macromolecules, 17, 2731 (1984).

7. C. Conio, E. Bianchi, A. Ciferri, and W. R. Krigbaum, Macromolecules, 17, 856 (1984).

8. M. N. Berger and B. M. Tidswell, J. Polym. Sci., Polym. Symp., 42, 1063 (1973).

9. H. Yamakawa and M. Fujii, Macromolecules, 7, 128 (1974).

10. H. Yamakawa and T. Yoshizaki, Macromolecules, 13, 633 (1980).

11. V. E. Shashoua, W. Sweeny, and F. R. Tietz, J. Am. Chem. Soc., 82, 866 (1960).

12. S. M. Aharoni, Macromolecules, 12, 94 (1979).

13. T. Norisuye, T. Yanaki, and H. Fujita, J. Polym. Sci., Polym. Phys. Ed., 18, 547 (1980).

14. S. V. Bushin, V. N. Tsvetkov, E. B. Lysenko, and V. N. Eml'yanov, Vysokomol. Soyedin, Ser. A, 23, 2499 (1981).

15. M. Bohdanecky, Macromolecules, 16, 1483 (1983)

16. A. Tonelli, Macromolecules, 7, 628 (1974). 